\section{Cross sectional area}

Helga Peter ${ }^{1}$ und Thomas Penzel ${ }^{2}$

${ }^{1}$ Marburg, Deutschland

${ }^{2}$ Interdisziplinäres Schlafmedizinisches Zentrum, Charité Universitätsmedizin Berlin, Berlin, Deutschland

\section{Englischer Begriff}

posterior airway space (PAS)

\section{Definition}

Atemwegsquerschnitt im Pharynxbereich. Kann durch akustische Verfahren am Tage liegend und sitzend bestimmt werden.

Siehe auch

- $>$ „Atmung“

- „Schnarchen“ 